\title{
Diploid models of the handicap principle
}

\author{
I. P. M. Tomlinson
}

Department of Genetics, Downing Street, Cambridge CB2 3EH, U.K.

\begin{abstract}
"Fisherian" models of sexual selection by female choice assume that females prefer male characters which are initially advantageous or neutral; character and preference then spread through the population. Once female preference has evolved to a higher frequency, the male character can become more extreme and disadvantageous by the action of some force such as the "super-normal stimulus". By contrast, the "handicap principle" of sexual selection proposes that females should prefer more extreme, disadvantaged males: males who survive the disadvantage of the "handicap" must be fitter in other respects. Previous models of various forms of the "handicap principle" have shown that it is very unlikely to work as an alternative to the "Fisherian process". However, recent haploid models have shown that a "condition-dependent handicap" might evolve. Diploid models show that the "condition-dependent handicap" model does not work. Models of "handicaps" operating together with the "Fisherian process" are also presented. It is inferred that "Fisherian" models are more likely than "handicap" models to account for the evolution of male sexual ornaments, although a "handicap" mechanism may aid the operation of the "Fisherian process".
\end{abstract}

\section{INTRODUCTION}

Darwin (1871) saw that the males of many species were often brightly coloured or possessed complex secondary adornments; females on the other hand were often cryptically coloured. To explain this, he proposed a theory of sexual selection by female choice: females preferred to mate with the bright, adorned males rather than cryptically coloured males. However, Darwin was unable to account for the evolution of the female preference.

In a polygynous population, preferred males have more mates than non-preferred males and thus produce more offspring. As long as character and preference are genetic, the offspring of preferential matings tend to carry genes for both the male character and female preference (Fisher, 1930). Thus, there will be a positive correlation between corresponding character and preference genes. Fisher thought that the character would increase in frequency exponentially and "drag" the preference through the population with it. Fisher called this a "runaway process"; more recent models (O'Donald, 1980) have confirmed Fisher's basic tenets but have shown that the increase in gene frequencies is often much slower than he thought.

The "Fisherian process" cannot apply in the same terms to monogamous populations. As each individual mates only once, preferred males have the same number of mates as non-preferred males. It must be assumed that preferred males produce more offspring by a means other than obtaining more mates. A mechanism was suggested by
Darwin (1871) and analysed by Fisher (1930): preferred males tend to find mates more easily, mate earlier in the breeding season in more favourable conditions and therefore gain a natural selective advantage. O'Donald (1983) showed that the melanic form of the monogamously-breeding Arctic skua (Stercorarius parasiticus) was preferred by females. He showed that this correlated with earlier breeding time and increased reproductive success. A form of the "Fisherian" process can then operate as it does in polygynous populations. A positive correlation develops between preferred character and preference alleles. Natural selection in favour of preferential maters causes the preference and character alleles to spread through the population together. Thus, a monogamous population can exhibit a form of "Fisherian" sexual selection, although the term "Fisherian" process is normally used to indicate a situation like that in a polygynous population where preferred males gain more mates.

Fisher himself did not believe that secondary male ornaments would always be favoured by natural selection. He supposed that the male character would initially possess a slight natural selective advantage, perhaps as a species recognition signal. As character and preference spread through the population, mechanisms like the "super-normal stimulus" (Staddon, 1975) cause the character to become more extreme and selectively disadvantageous until the advantage in sexual selection is balanced by the disadvantage in natural selection. Endler (1983) showed that there was a shifting balance between sexual selection in favour 
of bright colour patterns and natural selection for crypsis in different populations of the guppy Poecelia reticulata. In streams where levels of predation were higher, cryptic patterns were favoured. When a female preference has built up to higher levels, a greater natural selective disadvantage to the preferred character may be tolerated. The extreme male ornament is thus a form of "handicap", but its evolution is compatible with and, indeed, has been predicted by "Fisherian" theory.

What happens though if the secondary male character is initially disadvantageous? "Fisherian" theory predicts that both character and preference will be lost if natural selection outweighs the initial sexual selection advantage. However, the disadvantageous character might occur as a result of the effects of loci which confer increased Darwinian fitness on the carrier. For example, male Drosophila subobscura which court more vigorously are preferred by females (Maynard Smith, 1957). The more vigorous courters possess a "handicap" as their courtship depends on greater energy expenditure. They may, however, be using the "handicap" to signal their superior fitness to potential female mates. Models which assume that male characters are markers of quality are known as "handicap", "good genes" or "viability" models (Partridge and Harvey, 1986).

The "handicap principle" was put forward by Zahavi (1975) as an alternative to the "Fisherian" model. He claimed that exaggerated male traits and genetic female preferences for such traits could co-evolve, because the male trait imposed a handicap to the survival of the males which carried it. Males which carried the exaggerated trait and survived must have been superior in other respects such as speed of movement or food-gathering. He supposed that females would gain an advantage by mating with extreme, "handicapped" males because those "handicapped" males which survived would be sure to be "superior". "Non-handicapped" males which survived would not necessarily be "superior". The loci which caused the extra fitness were genetically distinct from loci for the exaggerated male trait. Females which preferred the handicapped males in mating would possess fitter offspring which would carry the genes which caused their fathers to be superior fliers, runners, etc. and also the genes for the female preference. Therefore, both preference and "handicap" would spread through the population.

"Handicap" models depend on the existence of heritable variation in fitness in the population, so that the "handicap" can correlate positively with increased Darwinian fitness in offspring. It had been thought that such variance was unlikely to exist in a population at equilibrium (Fisher, 1930; Maynard Smith, 1976a; Williams, 1975); if it did, fitness components would be negatively correlated or non-heritable. There are several reasons to think that suitable fitness variation might exist (Jones, 1987). Firstly, a population is unlikely to ever be truly at equilibrium. Secondly, only one (or a few) of the components of fitness needs to have high heritability. Thirdly, very many (if not all) alleles have effects on fitness and only one new mutation with superior fitness needs to arise; it is extremely unlikely that all organisms are perfectly adapted to their environment, especially if that environment changes frequently. Fourthly, many environments can produce additive genetic variation in fitness, especially if natural selection varies spatially or temporally.

When first proposed, Zahavi's principle caused considerable controversy among evolutionary biologists. For instance, O’Donald (1980), described Zahavi's proposition as "an extraordinary, even preposterous idea that directly contradicts Fisher's theory". O'Donald argued that the logical conclusion of Zahavi's theory was that females should prefer males with progressively greater deformities. There was also the problem that the offspring would inherit the "handicap": even if the "handicap" were only expressed in sons, it was argued, the disadvantage of the "handicap" must outweigh the increase in fitness. The analysis of formal genetic models has shown that unrealistic selective coefficients are necessary for Zahavi's "handicap principle" to account for the evolution of extreme male characters and female preferences. However, the "handicap principle" has since been redefined in broader terms in an attempt to show that some form of "handicap" can evolve. Zahavi assumed that expression of the "handicap" was independent of male fitness. The newer models assume that there are genetic interactions between the "handicap" and "superiority"; the "handicap" is expressed differently in, or has different effects on, fitter and less fit males.

\section{THE MODELS}

If it is not assumed that offspring of preferential matings have greater viability, the "Fisherian process" will not work in a monogamous population. Therefore, models of such a population can be used to study the effects of a "handicap" process in the absence of the "Fisherian process". Polygynous models can be used to study the combined 
effects of the "Fisherian" and "handicap" processes. In any polygynous population, it will be impossible to escape the effects of the "Fisherian" process. A summary of the genetic and fitness assumptions used in several of the diploid "handicap" models is given in table 1 , assuming that fitness is additive. Multiplicative fitnesses are used by some authors, but additive fitnesses are generally more favourable to the evolution of "handicaps".

The "handicap" mechanism will be most favoured if the fitness gene is rare initially. It has been argued (O'Donald, 1980) that the female preference gene will also enter the population at a low frequency. If the preference gene enters at a higher frequency, females must have a preference for a character that has not yet arisen. Females with a preference for males that do not exist will probably be at a natural selective disadvantage. They may waste time and energy in searching for non-existent males, even though they may eventually mate non-preferentially. Therefore, the preference allele will tend to be lost from the population. However, if a novel preference allele is introduced into a population in which the preferred character is already present, there may be very little disadvantage in mating preferentially, even if the preferred character itself is not common. This is especially likely if females sample cues from a variety of males before mating, as will occur at a lek. This viewpoint is not universally held; for example, Kirkpatrick (1982) believes that a preference may drift to high initial frequencies. I shall consider preference alleles to be at low initial frequencies in the "handicap" models, although higher initial frequencies do not substantially alter their conclusions.

Haploid (Bell, 1978; Andersson, 1982; Kirkpatrick, 1986b), polygenic (Kirkpatrick, 1986b) and diploid (Davis and O'Donald, 1976; Maynard Smith, 1976b, 1978; Tomlinson, unpubl.) models of the "Zahavi handicap" and "interactions handicap" show that they alone are insufficient to explain the evolution of male ornaments, even if additive genetic variance is present in the population. However, the "interactions handicap" may act to promote the operation of the "Fisherian process" under certain conditions (Andersson, 1982; Pomiankowski, 1987; Tomlinson, unpubl.).

Diploid models of sexual selection are known to show important differences of behaviour from the less realistic haploid models (O'Donald, 1980; Kirkpatrick, 1982). Previous models of the "condition-dependent handicap" (Andersson, 1986b) and "revealing handicap" (Kirkpatrick, 1986a)
Table 1 (after Maynard Smith, 1985) The table shows the fitnesses of each male phenotype under the five "handicap" models. "A" phenotype males are of genotype AA or Aa and possess the "handicap"; "a" phenotype males are of genotype aa and do not have the "handicap". " $B$ " phenotype males are of genotype $\mathrm{BB}$ or $\mathrm{Bb}$ and have increased fitness (except in the "pleiotropic handicap" where character and fitness are conferred by the A locus alone); "b" phenotype males are of genotype bb and do not have increased fitness. The "handicap" is assumed to be sex-limited and only male fitnesses are shown. The selective coefficients are equivalent to probabilities of survival and are positive. Phenotypes marked by * are preferred by females. Female selective coefficients are the same as those shown, but without any terms in $\beta$ and $\gamma$, because the "handicap" is only expressed in males. A dominant allele at a third locus, "C", confers a female preference for "handicapped" males. $\alpha=$ base line fitness; $\beta=$ loss of fitness owing to the handicap; $\gamma=$ additional cost of the handicap so that it is more serious in low viability males; $\varepsilon=$ gain in fitness owing to fitness allele $B$

(i) "Zahavi handicap" (Zahavi, 1975; Davis and O'Donald, 1976; Maynard Smith, 1976b)

$\begin{array}{lll} & \mathrm{A} & \mathrm{a} \\ \mathrm{B} & \alpha-\beta+\varepsilon^{*} & \alpha+\varepsilon \\ \mathrm{b} & \alpha-\beta^{*} & \alpha\end{array}$

(ii) "Interactions handicap" (Eshel, 1978; Zahavi, 1977; Bell, 1978; Maynard Smith, 1978; Andersson, 1982; Kirkpatrick, 1986b)

$\begin{array}{lll} & \mathrm{A} & \mathrm{a} \\ \mathrm{B} & \alpha-\beta+\varepsilon^{*} & \alpha+\varepsilon \\ \mathrm{b} & \alpha-\beta-\gamma^{*} & \alpha\end{array}$

(iii) "Condition-dependent handicap" (West-Eberhard, 1979; Maynard Smith, 1985; Andersson, 1986b)

$\begin{array}{lll} & \text { A } & \text { a } \\ \text { B } & \alpha-\beta+\varepsilon^{*} & \alpha+\varepsilon \\ \text { b } & \alpha & \alpha\end{array}$

(iv) Revealing handicap" (Hamilton and Zuk, 1982; Maynard Smith, 1985)

$\begin{array}{lll} & \mathrm{A} & \mathrm{a} \\ \mathrm{B} & \alpha-\beta+\varepsilon^{*} & \alpha+\varepsilon \\ \mathrm{b} & \alpha-\beta & \alpha\end{array}$

(v) "Pleiotropic handicap"

$\begin{array}{ll}\mathrm{A} & \alpha-\beta+\varepsilon^{*} \\ \mathrm{a} & \alpha\end{array}$

have assumed haploidy. In this paper, I present diploid models of the "condition-dependent handicap" and the "revealing handicap" in order to investigate any differences in behaviour. I present novel analysis of the "pleiotropic handicap". I also determine the effects of the "conditiondependent handicap" and "revealing handicap" in a polygynous population, that is with the "Fisherian process" operating. 


\section{RESULTS OF SIMULATIONS}

\section{(A) The condition-dependent handicap and the revealing handicap}

The "condition-dependent handicap" was proposed by West-Eberhard in 1979 (see Table 1(iii)). It assumes that the "handicap" is only developed by high-quality males that carry both the "handicap" gene and the fitness gene. Males with the "handicap" gene, but without the fitness gene, do not develop the "handicap" and consequently do not suffer a selective disadvantage because of it.

Andersson (1986b) used a three-locus (character, fitness, preference) haploid model to simulate the "condition-dependent handicap". He used a monogamous population to avoid the action of any "Fisherian" process. Genes for the "handicap", preference and fitness were assumed to be initially rare. He found that the fitness gene spread to fixation as expected. The "handicap" gene increased in frequency very slightly, but was lost as soon as the fitness gene approached fixation. A preference gene that did not reduce female viability initally increased in frequency. However, it also declined once the fitness allele neared fixation, although it was not necessarily lost from the population. A preference that carried a small cost could increase to a higher transient frequency, but was lost from the population once the fitness gene was fixed.

At first sight, the results suggest that a "condition-dependent handicap" cannot evolve. However, Andersson proposed that a new fitness gene might arise every few hundred generations. This might occur in some situation like a "hostparasite" arms race, or a "host-parasite" system under cyclical natural selection. If successive fitness genes arose, a "handicap" gene could very slowly "hitch-hike" through the population with each fitness gene. From an initial frequency of 0.001 , the "handicap" gene in Andersson's haploid model typically takes tens of thousands of generations to become fixed. The preference gene is also "dragged" through the population owing to its positive correlation with the fitness gene. However, the model lacks robustness: new fitness genes must arise at suitable times, or the period of oscillation must be suitable if natural selection is cyclical; the "handicap" gene is at a low frequency for about several thousand generations and must not be lost by drift during this time; and each fitness gene must be selectively advantageous until the next fitness gene arises. The model is unlikely to be able to provide a general mechanism for the evolution of male ornaments.
Might the "condition-dependent handicap" model apply in restricted cases? Andersson's results suggest that it might. I have independently constructed Andersson's haploid model and find identical results.

I have also analysed the "condition-dependent handicap" using a diploid model with dominant "handicap", preference and fitness genes. Again, a monogamous population is used in order to avoid the effects of the "Fisherian" process. It is impossible to derive analytic results for the diploid case, but it is possible to derive general conclusions mathematically and to draw a direct comparison with the mathematical results of Andersson.

When one fitness allele only is introduced into the population, results are qualitatively similar in diploids and haploids. There is a small transient increase in "handicap" and preference gene frequencies owing to their positive correlation with the fitness gene. The fitness gene spreads to fixation. However, the evolutionary process in diploid models is slower than in haploids, increasing the chances that preference and character will be lost when rare (see fig. 1). The transient increase

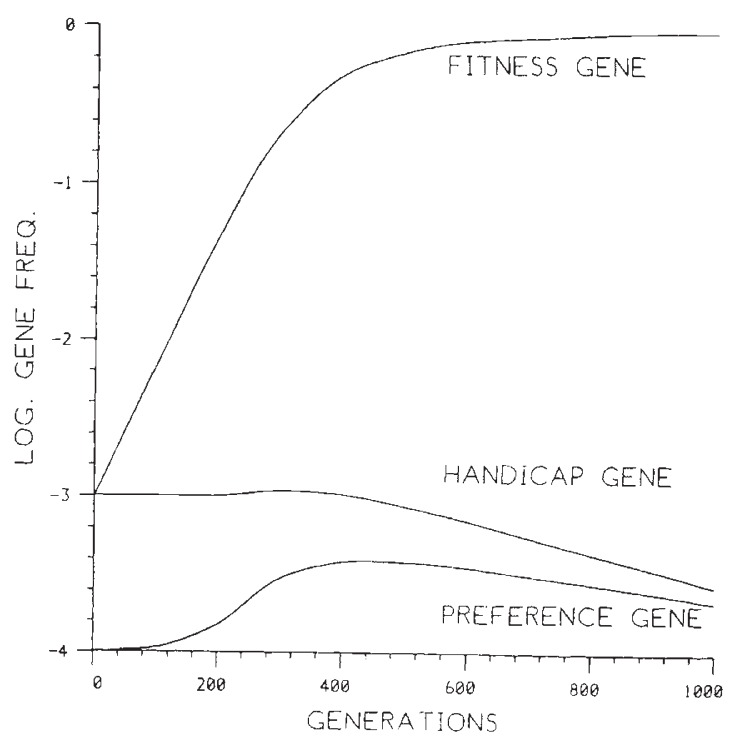

Figure 1 Graph illustrating the evolution in a monogamous population of a dominant male "condition-dependent handicap" gene and dominant female preference gene, both from initial frequencies of 0.001. A gene for extra fitness is present at an initial frequency of 0.0001 . Selective coefficients (Table 1 (iii)) are set at $\alpha=0 \cdot 1005 ; \beta=0.0005$; $\varepsilon=0.0020$. Comparison with the haploid model of Andersson (1986b) using the same initial values shows that gene frequency changes are slower and that the transient increases in "handicap" and preference gene frequencies are smaller. 
in gene frequencies is also smaller in a diploid population. In diploids, the positive correlations between the "handicap" and preference genes and the fitness gene are smaller, owing to the segregation of recessive genes from heterozygotes.

More importantly, I fail to obtain "handicap" gene fixation when successive fitness genes are introduced into the population. Initially, there may be a slow increase in "handicap" gene frequency. However, at all realistic value of the selective coefficients (and indeed at very many unrealistic selective coefficient values), this is followed by loss of the "handicap" gene from the population. The preference gene may increase in frequency, even if there is a small cost to a female expressing a preference. However, the preference gene spreads through the population as the "handicap" gene increases in frequency, but falls back as the "handicap" gene frequency declines (see fig. 2). In the models that I use, dominant "handicap", preference and fitness genes are more favourable to evolution of the "handicap" than recessive genes or genes with additive effects. For example, if "handicap" and preference genes are recessive, the "handicap" gene will generally decline from its initial frequency, with no transient increase in frequency.

Thus, diploid models predict that the "condition-dependent handicap" will not work in a monogamous population. In haploid models with suitable selective coefficients, the positive correlations between "handicap" and preference genes and the fitness genes are always sufficiently large that natural selection against the "handicap" may be overcome. Smaller correlations develop with diploidy; these are initially large enough to cause the spread of "handicap" and preference genes. However, the correlations eventually decline to such a level that the force of natural selection is strong enough to cause the observed decline in "handicap" and preference gene frequencies. The increase in "handicap" gene frequency appears to occur because most "handicapped" males are initially heterozygotes. Many of their male offspring will have extra fitness, but not the "handicap". However, all the male offspring of homozygous "handicapped" males will possess the "handicap". As homozygous "handicapped" males become more common, the small advantage to females in mating with "handicapped" males is lost and the "handicap" gene frequency enters an irreversible decline. The net evolutionary forces in diploid models are weak and genetic drift may be important in the possible evolution of "conditiondependent handicaps". It is conceivable that such

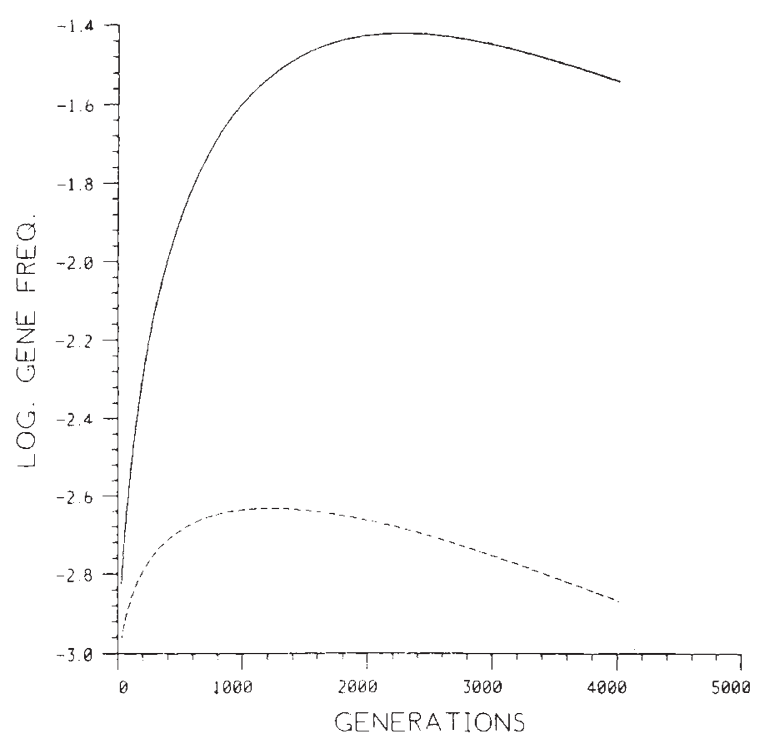

Figure 2 Graph illustrating the evolution in a monogamous population of dominant male "condition-dependent handicap" gene $(\rightarrow)$ and dominant female preference gene $(\cdots)$, both from intial frequencies of $0 \cdot 001$. Successive genes for extra fitness are assumed to arise every thirty generations at a frequency of 0.001 . Selective coefficients (Table 1(iii)) have been set so as to be favourable to evolution of the "handicap": $\alpha=0.10010 ; \beta=0.00010 ; \varepsilon=0.20000$; cost to females of expressing a preference $=0.00001 \times$ frequency of females with preference $\div$ frequency of males that have "handicap". The small cost of expressing a preference was shown (Andersson, 1986b) to be favourable to evolution of the "handicap". Maximum "handicap" and preference gene frequencies are attained if the new fitness gene is introduced whilst the "handicap" gene is at its highest frequency since introduction of the previous fitness gene. It may be seen that both "handicap" and preference genes increase in frequency slowly and then decline. They are eventually lost from the population, but this loss is so slow that it is not illustrated here.

a "handicap" may be rendered effectively "neutral" by the opposing natural and sexual selective forces and the "handicap" could spread through the population from its low initial frequency like a "neutral" allele. However, the "handicap" is more likely to drift out of the population than spread through it. I conclude that the "condition-dependent handicap" is very unlikely to work without the "Fisherian" process. In section 4 , I discuss whether it can work in the presence of the "Fisherian process".

The "revealing handicap" of Hamilton and Zuk (1982) (see table 1(iv)) is intuitively less likely to work than the "condition-dependent" handicap. In the former model, males with the "handicap" but without the extra fitness are at a selective disadvantage relative to such males in the latter 
model. There is thus greater natural selective pressure pushing the "handicap" gene out of the population in the "revealing handicap" model.

The "revealing handicap" was analysed by Kirkpatrick (1986a) using a three-locus haploid model and selective conditions somewhat different from those shown in table 1 . He assumed that one fitness (parasite resistance) allele was favoured for a number of generations and that another fitness allele was then favoured for the same number of generations. This process was repeated several times to model the effects of cyclical selection caused by host-parasite co-evolution. Kirkpatrick also assumed that there was female preference for both "handicapped" and cryptic males. He showed that the "handicap" gene would be lost unless the preference for it was at an unrealistically high initial frequency.

I have set up diploid simulations of the "revealing handicap" in a monogamous population, using the selective regime of Table 1(iv). The models assume that there is no female preference for cryptic males. Fitness is not cyclical in the way that Kirkpatrick assumed, but successive fitness genes can arise in the population (as they do for the "condition-dependent handicap" above). When only one fitness gene is introduced, results confirm that both the "handicap" gene and the preference gene increase less from their initial frequencies than if the "handicap" were "condition-dependent". If a succession of fitness genes is introduced (fig. 3), the "revealing handicap" shows similar behaviour to the "condition-dependent handicap". Again, there is a transient increase in "handicap" and preference gene frequencies, followed by a decline to below the starting values. Maximum frequencies are lower than in the case of the "condition-dependent handicap" and the decline in frequency is more severe. As expected, I conclude that the "revealing handicap" is even less likely to work in a monogamous population than is the "condition-dependent handicap". I consider the operation of the "revealing handicap" in polygynous populations (i.e. in conjunction with the "Fisherian" process) in section 4.

\section{(b) The pleiotropic handicap}

The "pleiotropic handicap" model (see Table 1(v)) assumes that a gene confers extra Darwinian fitness on all individuals that carry it. This gene also causes an ornament to develop in males only. This ornament is the object of a female preference, but lowers Darwinian fitness in the males that carry it (that is, it is a "handicap"). In practice, the net

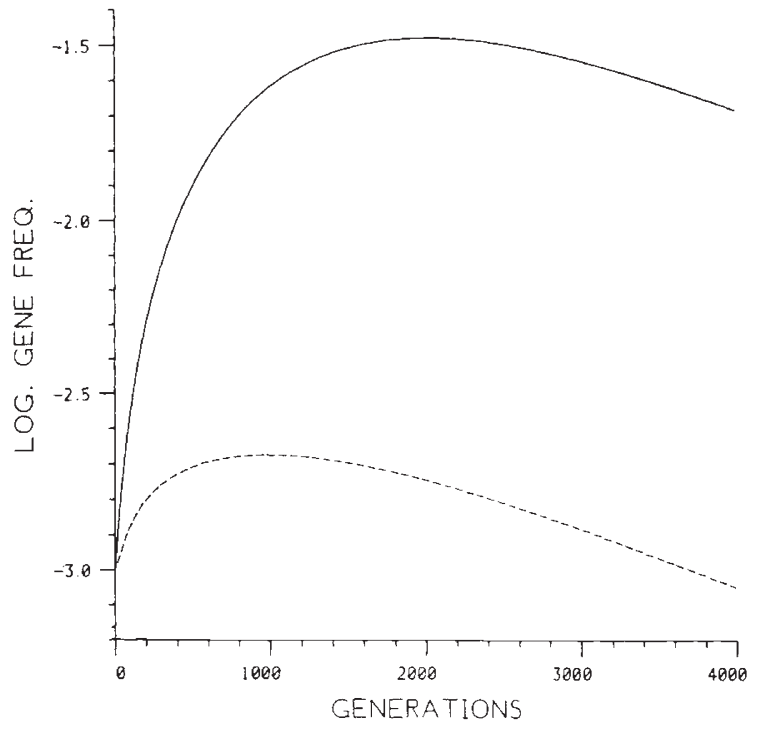

Figure 3 Graph illustrating the evolution in a monogamous population of dominant male "revealing handicap" gene $(\rightarrow)$ and dominant female preference gene $(-\rightarrow)$, both from initial frequencies of 0.001 . Successive genes for extra fitness are assumed to arise every thirty generations at a frequency of 0.001 . Selective coefficients (Table 1 (iv)) have been set so as to be favourable to evolution of the "handicap": $\alpha=0.10010 ; \beta=0.00010 ; \varepsilon=0.20000$; cost of preference $=0.00001 \times$ frequency of females with preference frequency of males that have "handicap". The graph is similar in form to that of the evolution of the "conditiondependent handicap", but shows that the "handicap" and preference genes have lower maximum frequencies and decline in frequency more rapidly.

fitness of males with an exaggerated display will often be greater than that of those without the display. The "pleiotropic handicap" assumes that the fitter males have no choice other than to display the "handicap". For example, a fruit fly with one or more genes for superior flying ability may court more actively because of those genes. The "handicapping" male ornament here is active courtship. There may be no alternative strategy open to the male fly, because a suitable mutation has never occurred. In a polygynous or a monogamous population, it is clear that the "handicap"/fitness gene and preference gene will spread if the net Darwinian fitness of "handicapped" males is greater than that of the other males. The preference gene will "hitch-hike" to a higher frequency with the "handicap"/fitness gene (see fig. 4).

However, alternative strategies may be open to a male. Suppose that there are two alleles at the "handicap/fitness" locus. The first allele is dominant and causes increased Darwinian fitness 


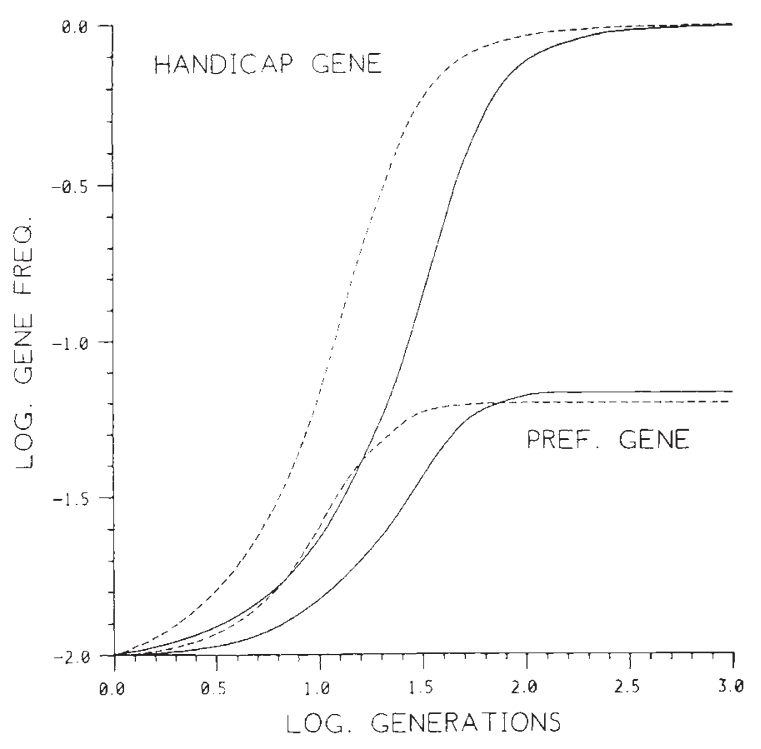

Figure 4 Graph illustrating the evolution in a monogamous population of a dominant "pleiotropic handicap/fitness" gene expressed in males and females and a dominant female preference gene. In the case shown by $(\rightarrow)$, the "handicap/fitness" gene confers a net extra fitness of 0.02 and in the case shown by $(\rightarrow)$ the extra fitness is 0.05 Fitnesses are additive and base survival probability is $0 \cdot 1$. Initial "handicap/fitness" and preference gene frequencies are 0.01 . The graph shows that the "handicap/fitness" gene spreads to fixation in both cases, although the increase in frequency is faster when the net extra fitness is higher. If no preference gene is incorporated, the spread of the "handicap/fitness" gene can be shown to be only slightly slower.

in individuals that carry it. It also causes males to develop an ornament ("handicap") which may be the object of a female preference and confers decreased Darwinian fitness on males that carry it. The second allele gives rise to cryptic, nonpreferred males when homozygous. Suppose too that there are two alleles at a female preference locus. The first allele is dominant and causes females to mate preferentially with males which possess the "handicap". The second allele is null. Individuals are diploid and reproduce monogamously, so that preferred males cannot gain by having more than one mate. Any advantage to preferential maters occurs because of a positive correlation between the preference gene and the "handicap/fitness" gene.

I shall consider two possible situations. In the first, a new "fitness only" allele arises at the "handicap/fitness" locus. This allele confers extra fitness of the same magnitude as did the original "handicap/fitness" allele, but expression of the male "handicap" is suppressed. In the second case, an allele arises at a third locus and this causes repression of the male "handicap" without affecting the extra fitness conferred by the "handicap/fitness" gene. In both cases, males with the novel phenotype lose out in sexual selection, but gain in natural selection as they do not possess any "handicap".

In the first alternative strategy, the novel allele for "fitness only" will probably be initially rare. The "handicap/fitness" allele will be initially common. Female preference gene frequency will have increased from a low initial frequency to a realistic value of, say, $0 \cdot 150$. At practically all values of selective coefficients, the "fitness-only" allele will slowly displace the "handicap/fitness" allele. The female preference allele will also be lost from the population, owing to its positive correlation with the "handicap/fitness" allele. If the "fitness only" allele confers a lower extra fitness than the fitness conferred by the "handicap/fitness" allele, there will be a threshold fitness above which the "fitnessonly" allele will spread and below which it will not enter the population.

In the second alternative strategy, the novel gene at the third locus for suppressing the male character will be initally rare. The "handicap/fitness" allele will be common and the female preference gene frequency will have increased from a low initial frequency to a value of, say, 0.150 as before. The novel gene actually has very little effect on gene frequencies. The "handicap/fitness" and preference genes are not displaced from the population. However, the allele for suppression usually increases in frequency, albeit very slowly. The proportion of males that express the ornament therefore also declines very slowly.

A "pleiotropic handicap" is a form of "revealing handicap", because males have no choice but to display their "value": the same genes control Darwinian fitness and male character. We have seen that this model can work, but it is susceptible to "invasion" by genes that cause the male "handicap" to be suppressed, but allow fitness to be retained. Problems also arise in explaining the origin of the male ornament. It is biologically unlikely that a fitness gene controls the form of the male display. Pleiotropy is sufficient to explain the variation of the extremity of the ornament with male condition, but is unlikely to explain how the ornament arose in the first place. Perhaps we need to invoke a "Fisherian" explanation for the origin of the ornament and of a genetic female preference. A "handicap" mechanism might then act to promote the spread of ornament and preference, as 
long as females prefer more extreme males. The preference for extreme ornaments need not be genetic; extreme males might act as "super-normal stimuli" and they would also be fitter. Thus, there would be a double pressure for the "handicap" to become more extreme.

\section{HANDICAPS IN POLYGYNOUS POPULATIONS}

I have already discussed the "Zahavi handicap" in a polygynous population as analysed by Maynard Smith (1976b). Andersson (1982, 1986a) showed that an "interactions handicap" could increase the rate of spread of a disadvantageous male character gene under "Fisherian" sexual selection, owing to "hitch-hiking" of the character and preference genes with the fitness gene. His haploid "interactions model" was modified to operate in a polygynous population in order to allow a "Fisherian" process to occur as well as the "handicap" process. However, the advantage to adorned males caused by the "Fisherian" mating advantage was found to be essential for the spread of the male character gene and female preference gene. Diploid models confirm Andersson's findings for the "interactions handicap". However, they also show that a pure "Fisherian" process with a neutral ornament allele is as likely to work as the mixed "interaction handicap/Fisherian" model, unless selective coefficients in the mixed model are extreme (see fig. 5).

Pomiankowski (1987) studied the "interactions handicap", "revealing handicap" and "conditiondependent handicap" in haploid, polygynous populations under conditions of cyclical natural selection. When the "handicap principle" operated in addition to the "Fisherian" process, he found that the probability of a male ornament becoming fixed in the population was increased; the "handicap" gene either spread to fixation if preference initally exceeded a threshold value, or was lost from the population. A higher preference gene frequency was also predicted. Indeed, under the "revealing handicap" or "condition-dependent handicap", fixation of the "handicap" gene was always accompanied by fixation of the preference gene.

I have analysed diploid models of the "condition-dependent handicap" and "revealing handicap" in polygynous populations under the selective regime used in section $3(\mathrm{a})$. When only one fitness gene is introduced into the population, the "Handicap" mechanism can act to potentiate the "Fisherian" process and higher final preference gene

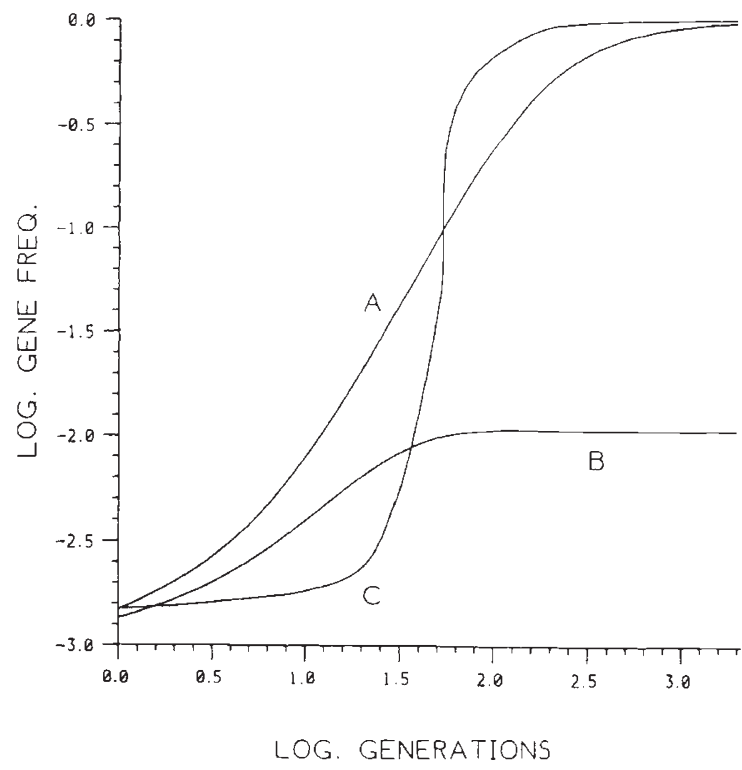

Figure 5 Graph illustrating the evolution in a polygynous population of a dominant male ornament gene. The ornament is the object of a dominant female preference. In case A, the process is pure "Fisherian" with a neutral ornament and no fitness gene incorporated; in case B, the process is pure "Fisherian" with a deleterious ornament that lowers probability of survival by 0.01 ; in case $C$, the process is a mixed "Fisherian/interactions handicap", with a disadvantageous ornament (that lowers probability of survival by 0.01 in fitter males and 0.055 in less fit males) and a fitness gene that confers extra probability of survival of 0.005 . The "ornament" gene and preference gene are both initially present at a frequency of 0.001 . Where incorporated, the fitness gene is present at an initial frequency of $0 \cdot 001$. Base survival probability is $0 \cdot 11$. All probabilities are additive. Typically, there is little difference between the "Fisherian" model with a neutral ornament and the mixed "Fisherian/interactions" model. The "Fisherian" model with a deleterious ornament shows the slowest evolution, although the male ornament may spread to fixation if it is less disadvantageous than shown here.

frequencies are predicted (see fig. 6). When more than one fitness gene is introduced, or selection is cyclical, the results of the diploid models confirm the conclusions drawn from the haploid simulations.

I believe that it is most useful to consider the "handicap" mechanism as a special case, acting in conjunction with the "Fisherian" process. Certain types of "handicap" may facilitate the working of the "Fisherian" process, but cannot work in its absence. Moreover, each "handicap" requires special conditions (for example, additive genetic variance in fitness) to work. 


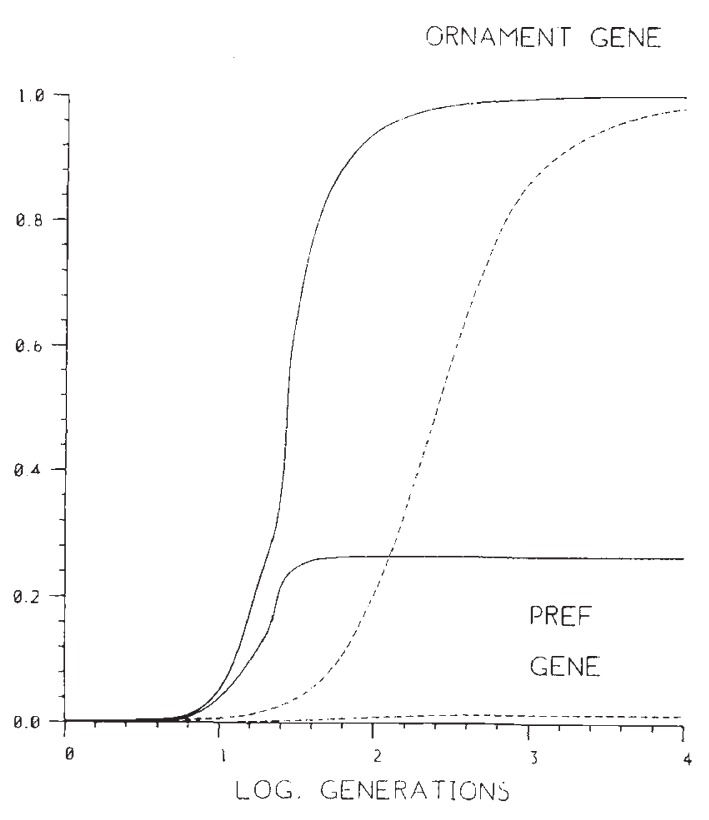

Figure 6 Graph illustrating the evolution in a polygynous population of a dominant male ornament gene and a dominant female preference gene. In the case shown by $(\cdots)$, the process is pure "Fisherian" with no fitness gene incorporated; in the case shown by $(\rightarrow)$, the process is mixed "Fisherian/condition-dependent handicap", with a locus that confers extra probability of survival of 0.002 . The ornament gene and preference gene are both initially present at a frequency of 0.001 . Where incorporated, the fitness gene is present at an initial frequency of 0.0001 . Base survival probability is $0 \cdot 1005$ and in both cases the ornament lowers probability of survival by 0.0005 . All probabilities are additive. The positive correlation between the character and preference genes and the fitness gene causes the mixed "Fisherian/condition-dependent handicap" process to be faster than the pure "Fisherian" process and to show higher final preference and ornament gene frequencies. A mixed "Fisherian/revealing handicap" is intermediate in nature. The mixed model therefore adds mathematical robustness to the pure "Fisherian" model, but requires more restricted biological conditions.

\section{THE DEGREE OF DEVELOPMENT OF HANDICAPS}

One of the difficulties of models of sexual selection is in explaining how male ornaments have evolved to the observed degree of extremity. "Fisherian" models assume that the ornament is initially "neutral" or advantageous. If the ornament shows variance in extremity, more extreme versions may act as "super-normal stimuli" to females. Female preference for such males is eflectively increased. If variance in trait extremity is heritable, the ornament tends to increase in extremity. This process may occur while ornament genes spread through the population and also when they are fixed, depending on whether the ornament is under polygenic or major genic control.

Ornament extremity is treated as an adaptation in several "handicap" models. Under the original "Zahavi handicap", a surviving more extreme male will have withstood a stronger natural selective disadvantage and so will be "fitter". Under the "revealing handicap", a more extreme male will be fitter. Under the "condition-dependent handicap", only very fit males can develop a very extreme "handicap". Females are assumed to prefer more extreme males, perhaps because of the "super-normal stimulus". Therefore, the pressure for ornaments to increase in extremity is two-fold: extreme males will be fitter in natural selective terms and they may also act as "super-normal stimuli".

It must be assumed that there is a limit to male ornament extremity, even if additive genetic variance for the ornament does not disappear. Eventually, stabilising natural selection is likely to act to restrain the development of the ornament, although it has not prevented the evolution of very extreme male traits like the tail of the widow-bird (Euplectes progne).

\section{DISCUSSION}

In conclusion, it is necessary to ask whether "handicap" models or "Fisherian" models are more likely to account for the evolution of secondary male sexual characters. It is difficult to gain experimental evidence for either model.

In support of "handicaps" (irrespective of the action of a "Fisherian" process also), it is necessary to show that the possession of an elaborated male character correlates positively with increased Darwinian fitness in other respects. It is notoriously difficult to measure Darwinian fitness. Hamilton and Zuk (1982) found a correlation between male brightness and parasite load across bird species; even though the original character might have arisen by a "Fisherian" mechanism, this appears to be a good contender as a "revealing handicap". Unfortunately, their study is inconclusive. Analysis could have been confounded by several artefacts and data was based on only a few parasite samples. Read (1987) found results across bird genera that were consistent with those of Hamilton and Zuk, even when the effects of taxonomic, behavioural and ecological variables were removed. However, explanations other than mate choice are possible; for example, bright birds may simply be more attractive to parasite vectors. 
Partridge (1980) found that mate choice can increase a genetic component of fitness in Drosophila melanogaster; however, it is possible, for example, that the preferred character itself was favoured in natural selection or that male competition was operating. There is also evidence that the additive genetic variance in fitness that is necessary for "handicap" models does in fact exist (Mackay, 1986).

There is also evidence for the "Fisherian" hypothesis. Sexual selection is more common in polygynous than monogamous populations (Darwin, 1871). This implies that the "handicap" process is unlikely to work on its own, without the "Fisherian" process, in agreement with the models. If preferential mate choice can be demonstrated and offspring do not have increased heritable offspring fitness, a purely "Fisherian" process is likely. However, an increased offspring fitness may be very difficult to detect.

Some evidence in support of the "Fisherian" process comes from studies on the two-spot ladybird Adalia bipunctata. The preferred character in this beetle is an effect of the melanic allele at the main colour pattern locus (O'Donald et al., 1984). Melanic males are preferred by females, but the melanic character is not sex-limited. Secondary sexual characters are often confined to males. However, female choice may be responsible for sexually monomorphic characters in species such as crown cranes, scarlet tiger moths, snow geese and Arctic skuas (Majerus, 1986). It is possible that a suitable mutation to sex-limit a disadvantageous character has not arisen in these species. However, the preferred character may not be sexlimited because it is actually advantageous, or was advantageous when female preference arose. For example, the melanic morphs of Adalia bipunctata may gain a thermal advantage in some regions of its habitat. "Handicap" models of female choice assume that the preferred character is a form of display and is thus disadvantageous to females. Females are concerned with choosing males, not displaying to them and would therefore not be expected to possess the "handicap". An advantageous preferred character is easily accomodated within the "Fisherian" hypothesis; either the character did not act as a "super-normal stimulus" and remained in its original advantageous state or the exaggerated character was not disadvantageous in natural selection.

It has been suggested (e.g., Partridge and Harvey, 1986) that male ornaments may act as species-recognition signals for pre-zygotic mating isolation. Suppose that two sibling species are in contact with each other. In both species, females choose mates, but cannot distinguish between the males of the two species. Therefore, many females will mate with males of the wrong species and suffer hugely decreased fitness as a consequence. Suppose now that a male ornament arises in one species, together in the same species with a female preference for that ornament. Therefore, any female with the preference will be sure of finding a mate of her species and will be at a large selective advantage. The preference gene will tend to spread through the population and pull the ornament gene with it; this is in contrast to the "Fisherian process" where the ornament gene pulls the preference gene through the population. Diploid simulations (Tomlinson, unpubl.) show that the advantage of extra fertility which is conferred by a male ornament is generally very high (50 per cent if the sibling species are equal in numbers); this advantage will usually outweigh any disadvantage as a result of, say, increased susceptibility to predators, unless that disadvantage is very large. As long as females can discriminate easily between preferred and non-preferred males, both preference and ornament will become fixed in the population. Discrimination will be easier if the male ornament is extreme or males possess more than one preferred ornament. However, it is debatable as to whether species recognition ornaments are strictly "handicaps", because the ornaments are associated with interspecific rather than intraspecific differences in fitness.

How robust are the "handicap" and "Fisherian" models? We have seen that models suggest that the "Zahavi handicap" does not work and that the "interactions handicap", "revealing handicap" and "condition-dependent handicap" are most unlikely to work without the "Fisherian process". "Pleiotropic handicap" genes are susceptible to being suppressed and may fail to explain satisfactorily how the character arose in the first instance, unless it was by a "Fisherian" process. All "handicap" models lack robustness in further areas: additive genetic variance of fitness must be present in the population; expression of a preference must not carry large costs; the gene for the male ornament must not be susceptible to "invasion" by a gene' that suppresses the male character; the "handicap" and the female preference must arise almost simultaneously if one is not to be lost by natural selection; and females must favour males with more extreme ornaments.

"Fisherian" models also lack robustness in certain areas; the male character must not be initially deleterious; in monogamous populations, there 
must be at least a small benefit to preferential maters; expression of a preference must not carry large costs; and some process such as the "supernormal stimulus" must act to make the character more extreme.

In general, evidence from studies such as those of Hamilton and Zuk (1982) and of O'Donald (1983) is potentially of much use in suggesting which models may be most realistic. However, even the results of these workers do not conclusively distinguish between the actions of a "Fisherian" process, a "handicap" process or a combination of the two processes. Andersson's paper (1987) to the Dahlem Conference on sexual selection casts doubt on the feasibility of testing such complex models.

With the possible exception of the "pleiotropic handicap", I conclude that the "handicap principle" is unlikely to work in diploid or polygenic populations, in the absence of the "Fisherian" process. I believe that models of the "Fisherian" process have greater robustness in explaining the evolution of male ornaments. However, certain types of "handicap", especially if "conditiondependent" or "revealing", may operate to enhance the effects of the "Fisherian" process. For example, a combined "Fisherian" and "conditiondependent handicap" system can explain the evolution of a male ornament that is initially extreme, without the need to invoke the "supernormal stimulus" mechanism. The importance of "handicap" models may not lie in contradicting Fisher, but rather in supporting him.

Acknowledgements I am grateful for invaluable help given by Drs P. O'Donald, M. E. N. Majerus, P. W. E. Kearns and C. Veltman and to $\mathrm{Mr}$ R. J Howlett and an unknown referee. I am also indebted to the SERC for a Quota Award and to the Wolfson Foundation for providing laboratory facilities.

\section{REFERENCES}

ANDERSSON, M. 1982. Sexual selection, natural selection and quality advertisement. Biol. J. Linn. Soc., 17, 375-393.

ANDERSSON, M. 1986a. Sexual selection and the importance of viability differences: a reply. $J$. theor. Biol., 120, 251-254.

ANDERSSON, M. 1986 b. Evolution of condition-dependent sex ornaments and mating preferences; sexual selection based on viability differences. Evolution, 40, 804-816.

ANDERSSON, M. 1987. Genetic models of sexual selection: some aims, assumptions and tests. Bradbury, J. W. and Andersson, M. (eds). In Sexual Selection; Testing the Alternatives. Dahlem Konferenzen. Springer-Verlag, Berlin, Heidelberg, New York.

BELL, G. 1978. The handicap principle in sexual selection. Evolution, 32, 872-885
DARWIN, C. 1871. The Descent of Man and Selection in Relation to Sex. John Murray, London.

DAVIS, J. W. F. AND O'DONALD, P. 1976. Sexual selection for a handicap: a critical analysis of Zahavi's model. J. theor. Biol., 57, 345-354.

ENDLER, J. A. 1983. Natural and sexual selection on colour patterns in poeciliid fishes. Env. Biol. Fishes, 9, 173-190.

ESHEL, 1. 1978. On the handicap principle-a critical defence. J. theor. Biol., 70, 245-250.

FISHER, R. A. 1930. The Genetical Theory of Natural Selection. The Clarendon Press, Oxford.

HAMILTON, W. D. AND ZUK, M. 1982. Heritable true fitness and bright birds; a role for parasites? Science, 218, 384-387.

JONES, J. S. 1987. The heritability of fitness: bad news for "good genes"? Trends Ecol. Evol., 2, 35-38.

KIRKPATRICK, M. 1982. Sexual selection and the evolution of female choice. Evolution, 36, 1-12.

KIRKPATRICK, M. 1986a. Sexual selection and cycling parasites: a simulation study of Hamilton's hypothesis. J. theor. Biol., 119, 263-271.

KIRKPATRICK, M. $1986 \mathrm{~b}$. The handicap mechanism of sexual selection does not work. Amer. Natur., 127, 222-240.

MACKAY, T. F. C. 1986. A quantitative genetic analysis of fitness and its components in Drosophila melanogaster. Genet. Res., 47, 59-70.

MARJERUS, M. E. N. 1986. The genetics and evolution of female choice. Trends Ecol. Evol., 1, 1-7.

MAYNARD SMITH, J. 1956. Fertility, mating behaviour and sexual selection in Drosophila subobscura. J. Genet., 54, 261-279.

MAYNARD SMITH, J. 1976a. The Evolution of Sex. Cambridge University Press, Cambridge.

MAYNARD SMITH, 3. 1976 b. Sexual selection and the handicap principle. J. theor. Biol., 57, 239-242.

MAYNARD SMITH, 3. 1978. The handicap principle-a comment. J. theor. Biol., 70, 251-252.

MAYNARD SMITH, J. 1985. Sexual selection, handicaps and true fitness. $J$. theor. Biol., 115, 1-8.

O'DONALD, P. 1980. Genetic Models of Sexual Selection. Cambridge University Press, Cambridge.

O'Donald, P. 1983. The Arctic Skua. Cambridge University Press, Cambridge.

O'DONALD, P., DERRICK, M., MAJERUS, M. E. N. AND WEIR, J. 1984. Population genetic theory of the assortative mating, sexual selection and natural selection of the two-spot ladybird Adalia bipunctata. Heredity, 52, 43-61.

PARTRIDGE, L. 1980. Mate choice increases a component of offspring fitness in fruit flies. Nature, 283, 290-291.

PARTRIDGE, L. AND HARVEY, P. 1986. Contentious issues in sexual selection. Nature, 323, 580-581.

POMIANKOWSKI, A. 1987. Sexual selection: the handicap principle does work-sometimes. Proc. R. Soc. Lond. B., 231, 123-145.

READ, A. F. 1987. Comparative evidence supports the Hamilton and Zuk hypothesis on parasites and sexual selection. Nature, 328, 68-70.

STADDON, J. E. R. 1975. A note on the evolutionary significance of "supernormal stimuli". Amer. Natur., 109, 541-545.

WEST-FBERHARD, M. J. 1979. Sexual selection, social competition and evolution. Proc. Am. Phil. Soc., 123, 222-234.

WILliamS, G. C. 1975. Sex and Evolution. Princeton University Press.

ZAHAVI, A. 1975. Mate selection-a selection for a handicap. J. theor. Biol., 53, 205-214.

ZAHAVI, A. 1977. The cost of honesty (further remarks on the handicap principle). J. theor. Biol., 67, 603-605. 